\title{
Biodiversity of pollen in indoor air samples as revealed by DNA metabarcoding
}

\section{Korpelainen, Helena}

2017-10

Korpelainen , H \& Pietiläinen , M 2017 , ' Biodiversity of pollen in indoor air samples as revealed by DNA metabarcoding ' , Nordic Journal of Botany , vol. 35 , no. 5 , pp. 602-608 . https://doi.org/10.1111/n http://hdl.handle.net/10138/307916

https://doi.org/10.1111/njb.01623

acceptedVersion

Downloaded from Helda, University of Helsinki institutional repository.

This is an electronic reprint of the original article.

This reprint may differ from the original in pagination and typographic detail.

Please cite the original version. 
1 Revision

2

3

4

5 Biodiversity of pollen in indoor air samples as revealed by DNA

6 metabarcoding

7

8

9 Helena Korpelainen* and Maria Pietiläinen

10

11 Department of Agricultural Sciences, Viikki Plant Science Centre, P.O. Box 27, FI-00014

12 University of Helsinki, Finland

13

14

15

$16 *$ Corresponding author

17 E-mail: helena.korpelainen@ helsinki.fi

18 Phone: +358 294158383

19 
We conducted DNA metabarcoding (based on the nuclear ITS2 region) to characterize indoor

21 pollen samples (possibly accompanied by other plant fragments) and to discover whether there are seasonal changes in their taxonomic diversity. It was shown that DNA metabarcoding has potential to allow a good discovery of taxonomic diversity. The numbers of spermatophyte families and genera varied greatly among sampling sites (pooled results per building) and times, between 9-40 and 10-66, respectively. Comparable Shannon's diversity indices equaled 0.332.76 and $0.94-3.16$. The total number of spermatophyte genera found during the study was 187 , of which 43.9, 39.6, 7.5 and 9.1\% represented wild, garden/crop and indoor house plants, and non-domestic fruit or other plant material, respectively. Comparable proportions of individual sequences equaled $77.4,18.8,2.7$ and $1.1 \%$, respectively. When comparing plant diversities and taxonomic composition among buildings or between seasons, no obvious pattern was detected, except for the second summer, when pollen coming from outdoors was highly dominant and the proportions of likely allergens, birch, grass, alder and mugwort pollen, were very high. The

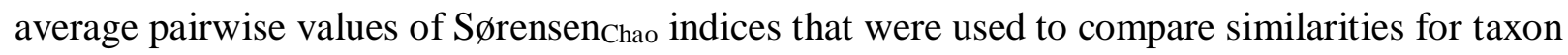
composition between samples among the samples from the two university buildings, two nurseries and farmhouse equaled $0.514,0.109,0.564,0.865$ and 0.867 , respectively, while the mean similarity index for all samples was 0.524 . Cleaning frequency may strongly contribute to the observed diversity. The discovery of considerable diversities, including pollen coming from outside, in both winter and summer shows that substantial amounts of pollen produced in summer enter buildings and stay there throughout the year. diversity, pollen, seasonal variation, taxonomic composition 
Particles of indoor environments, such as dust mites, mold, bacteria, viruses, pet dander and pollen, are major environmental concerns for human wellbeing, as they can cause severe health problems (Chapman et al. 2007). Some of them, like viruses and bacteria, cause infections, while others cause allergies in susceptible persons, possibly very serious ones. There are estimates that nowadays allergic diseases caused by plant, animal and fungal allergens affect even more than $30 \%$ of the population in industrialized countries (Crameri et al. 2014).

Pollen can enter buildings through open windows and doors, and people track pollen indoors on their shoes, clothes and hair. Pollen counts are higher in the spring and summer, although it can remain indoors through other seasons as well. Pollen of most plant species has some level of allergenicity but some types are particularly notorious for inducing symptoms of hay fever. In Finland, in the area of this study, the most problematic types of pollen are those of grasses (Poaceae), birch (Betula sp.), alder (Alnus sp.) and mugwort (Artemisia vulgaris) (Jantunen et al. 2012). Current pollen monitoring methods are microscope-based and laborintensive. Although pollen of each taxon has its own unique set of characteristics, it is very timeconsuming and sometimes impossible to comprehensively determine the taxonomic composition of these tiny particles in air samples without molecular tools (Khansari et al. 2012, Galimberti et al. 2014).

Recent advances in DNA sequencing provide effective tools for species identification and biomonitoring using DNA present in the environment. DNA barcoding through high-throughput sequencing (next generation sequencing) allows the characterization of the species composition of bulk samples, including both intact and degraded DNA extracted from environmental samples (e.g. Taberlet et al. 2012, Bohmann et al. 2014), for example investigations on honey bee pollen foraging and honey composition (Galimberti et al. 2014, Bruni et al. 2015, Cornman et al. 2015, Hawkins et al. 2015, Keller et al. 2015), vegetation analyses in lake sediments (Parducci et al. 2013) and pollen monitoring in air (Kraaijeveld et al. 2015). Such DNA metabarcoding uses 
universal PCR primers to mass-amplify a taxonomically informative gene from bulk samples.

Recently, we analysed fungal diversity in indoor air by DNA metabarcoding (Korpelainen et al. 2016, Korpelainen and Pietiläinen 2017) and now extend the analysis to plant particles. In the present study, our aim was to increase precision in analyses on pollen and plant fragments and to provide useful data and tools for investigations on the quality of indoor spaces. Our additional goal was to discover, whether there are seasonal changes in the biodiversity of plant materials in indoor spaces. We chose to use the nuclear ITS2 region, because prior investigations support its universal nature (good PCR amplifiability across taxa) and suitability for differentiating plant taxa in pollen samples at the genus and, in some cases, at the species level (e.g. Richardson et al. 2015a, Sickel et al. 2015), although there is also indication that plastid markers, such as matK and and trnH-psbA, may be more effective when characterizing the diversity of pollen samples (Richardson et al. 2015b).

\section{Material and methods}

Samples were collected from five buildings, including two university buildings, two nursery schools and an old farmhouse. The farmhouse is located in the county of Porvoo, about $40 \mathrm{~km}$ to the east from Helsinki, while other buildings are located in Helsinki (about $60^{\circ} 14^{\prime} \mathrm{N}, 25^{\circ} 01^{\prime} \mathrm{E}$ ). The distance between the two nursery schools is about $6 \mathrm{~km}$, and the distance between the two university buildings is $0.2 \mathrm{~km}$, while the distances between each nursery school and both university buildings are about 12 and $7 \mathrm{~km}$, respectively. The large university buildings and the single-floor nursery school buildings are surrounded by lawns, bushes and primarily broadleaved trees. The farmhouse is surrounded by a lawn, kitchen garden and fields of cereal crops, and there are many types of trees nearby. Sampling was conducted four times: January 2013, July 2013, January 2014, and July 2014. All buildings were not sampled on every occasion

(Table 1). Both nursery schools were renovated during the study due to minor water damage and 
115 Forward ITS4 mix including three primers:

116 ITS4_F1 5'-ATCTACACTCTTTCCCTACACGACGCTCTTCCGATCTTCCTCCGCTTATTGATATGC-3'

observed mould growth, and we sampled them both before and after renovation. Indoor sampling was conducted using a collector with a disposable filter (DUSTREAM ${ }^{\mathrm{TM}}$ Collector, Indoor Biotechnologies Inc., Charlottesville, VA, USA; mesh size $40 \mu \mathrm{m}$ ) attached to the tube of a vacuum cleaner with the suction power of $32 \mathrm{~L} / \mathrm{s}$. Both a horizontal (tables or shelves) and vertical (walls) sample were collected by vacuuming an area of about $2 \mathrm{~m}^{2} /$ sample (i.e., two $2 \mathrm{~m}^{2}$ samples per room) from two rooms in each of five buildings (two office rooms in each university building, two playrooms in each nursery school, and two bedrooms in the old farmhouse). After vacuuming, the filter containing the dust was removed from the collector and placed in a plastic bag until processing, involving cutting the filter, rinsing the filter with water and emptying the content to a petri dish, where large non-biological particles were removed. Thereafter, the samples were dipped in liquid nitrogen and ground in a ball mill, and DNA was extracted using the CTAB method (Doyle and Doyle 1987). The final volume was $100 \mu 1$. For DNA metabarcoding, genomic ITS2 sequences were amplified and sequenced using two approaches. All sequencing was conducted at the DNA Sequencing and Genomics Laboratory, Institute of Biotechnology, University of Helsinki. The sequencing for the samples from January and July 2013 were conducted using 454 FLX pyrosequencing (Roche Applied Science, Penzberg, Germany), as described in Korpelainen et al. (2016), while sequencing for the samples from January and July 2014 were performed using Illumina MiSeq sequencing (San Diego, CA, USA), for which ITS2 sequences were first amplified using the following primer system (forward ITS4 mix + reverse ITS3 mix) (see Korpelainen and Pietiläinen 2017): ITS4_F2 5'-ATCTACACTCTTTCCCTACACGACGCTCTTCCGATCT(c/g)TCCTCCGCTTATTGATATGC-3 ITS4_F3 5'-ATCTACACTCTTTCCCTACACGACGCTCTTCCGATCTagt(a/g)(a/g)TCCTCCGCTTATTGATATGC-3' 
120 Reverse ITS3 mix including three primers: sample sizes (Chao et al. 2005).

All 20- $\mu 1$ PCR reactions contained $2 \mu 1$ of template DNA. After sequencing, primer sequences were removed from the raw reads, and quality control, as described by Brown et al. (2013), followed. During this process, low-quality reads (below average PHRED score of 25) and short sequences $(<100 \mathrm{bp})$ were removed. Then, all other sequence data were subjected to similarity search against GenBank (www.ncbi.nlm.nih.gov/genbank), and assignment of taxonomic identities using TAXAassign (https://github.com/umerijaz/ taxaassign) was conducted with 95 and $97 \%$ thresholds for genus and species levels, respectively. The 97\% threshold is, by convention, used as a divergence threshold for operational taxonomic units (OTUs) that serve as a proxy for species (Brown $\boldsymbol{e t}$ al. 2015). The sequence data were submitted to the EMBL (European Molecular Biology Laboratory) database under accession number PRJEB8345. Based on the numbers of sequences representing each taxon (i.e., taxon distribution), Shannon's diversity indices (Shannon 1948) were calculated at family and genus levels for each sample. In addition, EstimateS 9.1.0. (http://purl.oclc.org/estimates) was used to calculate similarities for taxon composition between pooled longitudinal samples (each including all four samples from a building at the same time point). The used estimator was the Sørensen Chao $_{\text {abundance- }}$ based similarity index (corrected for unseen shared species), which can also handle different 
145 As a result of DNA metabarcoding, good-quality sequences were obtained. Small-scale

146 pyrosequencing was conducted for the two first sets of samples (winter 2013 and summer 2013),

147 and the total number of good sequences averaged 26276 and 19868 sequences/building.

148 However, the majority of the sequences represented fungi, and the average numbers of

149 spermatophyte sequences equalled 613 (range 109-1 493) and 537 (range 249-726)

150 sequences/building. For the last two sets of Illumina-sequenced samples (winter 2014 and

151 summer 2014), the total numbers of good sequences were on average 855576 and 2235022

152 sequences/building, respectively, while the mean numbers of spermatophyte sequences among 153 them equalled 664 (range 399-1041) and 5934 (range 482-10953), respectively.

154 It is notable that there were no major changes in spermatophyte sequence numbers between

155 winter samples analysed with different sequencing approaches, while Illumina-based analyses in 156 summer 2014 revealed high numbers of sequences, 6360 and 10954 sequences in Nursery 1 and

157 2, respectively, which equal to 10-100 -fold increases compared to sequence numbers in 2013

158 when 454 FLX pyrosequencing had been used. However, the third building, University 1,

159 analysed in summer 2014, showed an even slightly lower number of sequences (change from 726

160 to 482 sequences between summers). The used method is effective until the genus-level

161 identification of spermatophytes $(99.7 \%)$, but ITS2 alone is not satisfactory for the species-level

162 identification (only $18.0 \%$ of the samples). Here, we present diversity and taxonomic

163 information based on genus level data unless specified differently.

164 The numbers of spermatophyte families and genera per sample varied greatly among

165 sampling sites (pooled results per building) and times, between 9-40 and 10-66, respectively

166 (Table 1). Comparable ranges of Shannon's diversity indices were 0.33-2.76 and 0.94-3.16,

167 respectively. The total number of spermatophyte genera found during the study was 187 , of

168 which 43.9, 39.6, 7.5 and 9.1\% represented wild, garden/crop plants, indoor house plants, and 
non-domestic fruit or other plant material, respectively. Comparable proportions of individual

170 sequences equaled 77.4, 18.8, 2.7 and $1.1 \%$, respectively. Proportions of these four groups of

171 plants, based on sequences numbers, showed great variation among buildings and seasons (Fig.

172 1). In the last samples from July 2014, a great majority, almost $100 \%$ of sequences, represented

173 pollen coming from outdoors (wild and garden/crop plants); also the proportions of sequences

174 representing likely allergens, birch, grass, alder and mugwort pollen, were then very high, 58.5\%

175 (24.1\% in the whole dataset). Both the winter and summer samples of the farmhouse possessed very high proportions of outdoors pollen material (94.8 and $99.3 \%$ of sequences, respectively). The change in the sequencing method and differences in numbers of sequences between the first two and last two sampling times (particularly summer 2014) did not show in diversity

179 indices (genus level, determined for individual samples) that equalled $1.82 \pm 0.70$ and $1.59 \pm 0.90$

$180(\mathrm{t}=0.766, \mathrm{p}=0.451, \mathrm{df}=26 ; \mathrm{t}$ test $)$, respectively. However, concerning the numbers of detected

181 taxa, there was a significant increase, the genus numbers equalling $21.4 \pm 13.0$ and $34.6 \pm 15.6$ $(\mathrm{t}=2.452, \mathrm{p}=0.021, \mathrm{df}=26)$, respectively. The numbers of taxa were closely similar among individual horizontal and vertical samples, on average $26.2 \pm 16.7$ and $27.5 \pm 14.5 \mathrm{t}=0.211$,

$184 \mathrm{p}=0.834, \mathrm{df}=26$ ), respectively, as also the diversity indices, on average $1.65 \pm 0.91$ and $1.81 \pm 0.7$ $185(\mathrm{t}=0.536, \mathrm{p}=0.597, \mathrm{df}=26)$, respectively. Comparable values for individual winter and summer samples showed that there was a tendency to a higher diversity in summer, the values equalling 21.3 \pm 14.1 and $31.6 \pm 15.2(\mathrm{t}=1.8657, \mathrm{p}=0.073, \mathrm{df}=26)$, respectively, and $1.63 \pm 0.58$ and $1.81 \pm 0.93$ $(\mathrm{t}=0.619, \mathrm{p}=0.541, \mathrm{df}=26)$, respectively.

Table 2 lists the five most frequent plant taxa detected in each building at each sampling

190 time. The results show that there was a great turnover in the proportions of different taxa.

191 Brassica sp. was found among top-five taxa in 10 out of 14 building samples (detected in all

192 building samples), Betula sp. in 9 out of 14 building samples (detected in 12 out of 14 building

193 samples), and the common house plant Saintpaulia sp. and the common garden ornamental 
Syringa sp. both were among top-five taxa in 4 out of 14 buildings (Table 2). In several samples,

195 one specific taxon was highly dominating, such as Aegopodium sp. in University 1 in winter 2013 (56.5\%), Brassica sp. in University 2 in winter 2013 (55.0\%), Fallopia sp. in University 2 in summer 2013 (64.2\%), Ficus sp. in Nursery 1 in summer 2013 (52.4\%), Syringa sp. in

198 Farmhouse in winter 2014 (83.3\%), and Betula sp. in Nursery 1 and Nursery 2 in summer 2014 199 (47.9 and 97.9\%, respectively).

Sørensen ${ }_{\text {Chao }}$ indices that were calculated to compare similarities for taxon composition between samples did not show any clear pattern. The average pairwise values for temporal pooled samples among University 1, University 2, Nursery 1, Nursery 2 and farmhouse samples equaled $0.514,0.109,0.564,0.865$ and 0.867 , respectively, while the mean similarity index for

204 all samples was 0.524 . The similarity indices of Nursery 1 and Nursery 2 samples for before and 205 after renovation samples equaled 0.333 and 0.865 , respectively. For comparison, Shannon's 206 genus-level diversity indices of Nursery 1 equaled 1.80 and 1.59 before and after renovation, and those of Nursery 2 equaled 2.53 and 1.01 , respectively.

\section{Discussion}

210 DNA metabarcoding was conducted successfully for pollen samples (possibly accompanied by

211 other plant particles) collected from indoor spaces in five buildings, including two university

212 buildings, two nursery schools and an old farmhouse. The change of sequencing method from

213454 FLX pyrosequencing (winter 2013 and summer 2013 samples) to Illumina MiSeq

214 sequencing (winter 2014 and summer 2014 samples) and resulting increases in sequence

215 numbers (especially for summer 2014 samples) are suggested to increase the detection of

216 infrequent taxa, with the mean number of genera per building increasing from 22 to 35 .

217 However, temporal variation, partly due to human effects, such as cleaning frequency, may

218 contribute to changes in numbers of sequences and detected taxa. Considering sequencing 
platform qualities, Kozich et al. (2013) have demonstrated that Illumina MiSeq platform can

220 provide data that are at least as good as that generated by the 454 platform while providing

221 higher sequencing coverage at a lower cost. Nelson et al. (2014) have also discussed how well

222 Illumina sequencing could serve as a direct replacement for 454 pyrosequencing. They showed

223 in diversity analyses on microbial communities based on the $16 \mathrm{~S}$ region that moving to Illumina-

224 based sequencing platforms provides deeper insights into the breadth of diversity, but they

225 pointed out that care must be taken to ensure that sequencing and processing artefacts do not

226 obscure the results. Recently, Castelino et al. (2017) have also shown that Illumina provides

227 comparable data to 454 pyrosequencing, with a similar capture of diversity but with a much

228 improved throughput and cost effectiveness.

Plant diversities in samples collected from different buildings (university offices, nursery

230 schools and a farmhouse) and during different seasons (summer vs. winter) showed considerable

231 variation and turnover but no definite pattern, although there was a slight tendency to a higher

232 diversity in summer. Also, Sørensen ${ }_{\text {Chao }}$ indices that were calculated to compare similarities for

233 taxon composition between samples did not show any clear pattern. The mean similarity index

234 for all samples was 0.524 , while the similarity indices of Nursery 1 and Nursery 2 samples for

235 before and after renovation samples equalled 0.333 and 0.865 , respectively. For comparison,

236 Shannon's genus-level diversity indices of these nursery samples were lower after renovation,

237 which may relate to extensive cleaning of buildings after renovation.

The proportions of wild, garden/crop plants, indoor house plants, and non-domestic fruit

239 or other plant material, based on sequences numbers in our analyses, showed great variation

240 among buildings and seasons. In several samples, one specific taxon was highly dominating. In

241 the last sample set from July 2014 almost $100 \%$ of sequences represented plants coming from

242 outdoors (wild and garden/crop plants), and the proportions of sequences representing likely

243 allergens, birch, grass, alder and mugwort pollen, were then very high (58.5\%). Both the winter 
and summer samples of the farmhouse possessed very high proportions of outdoors plant material (94.8 and 99.3\%), which may relate to the rural setting and perhaps even more to the lack of air conditioning and frequent opening of windows for cooling and air renewal, thus facilitating the penetration of pollen from outside. building emphasizes the importance of multiple sampling. A considerable presence of certain 250 allergy-inducing plants, such as birch (Betula sp.) and grasses (Poaceae), may be good indicators of indoor air quality (as far as plant particles are concerned) and may indicate the need of improved cleaning or air purification. Besides seasonality, cleaning frequency and coverage in different buildings may strongly contribute to the observed diversity and pattern of plant particles, although all studied buildings are cleaned regularly. The discovery of considerable diversities, including also pollen coming from outside, in both winter and summer shows that substantial amounts of pollen produced in summer enter buildings and stay there throughout the year, as previously observed also by Pichot et al. (2015).

DNA metabarcoding is considered as an effective tool for biodiversity investigations, and its effectiveness is already well proven for a range of organisms and environments, and even for 260 poor-quality and low-quantity DNA (e.g. Taberlet et al. 2012, Bohmann et al. 2014, Korpelainen et al. 2016, Korpelainen and Pietiläinen 2017). The approved standard barcode for the land plants is a two-locus DNA barcode, including a portion of coding chloroplast genes rbcL and matK (CBOL Plant working group 2009). However, for the purpose of our analysis, a single-

264 region approach was more practical. While rbcL does not provide satisfactory species 265 discrimination power (CBOL Plant working group 2009), matK is often difficult when dealing 266 with multiple plant families (Heckenhauer et al. 2016, H. Korpelainen pers. obs.). Therefore, we 267 decided not to use the universal two-locus plant barcode but chose the ITS region, specifically 268 ITS2. 
Previously, Keller et al. (2015), Richardson et al. (2015a) and Sickel et al. (2015) have

analysed pollen samples using both microscopy and DNA metabarcoding (the ITS2 barcode) and

271 they found that metabarcoding exhibited higher sensitivity for identifying taxa present in large

272 and diverse pollen samples relative to microscopy. It is also a benefit that metabarcoding does

273 not require a high level of taxonomic expertise. Additional plastid markers, such as matK and

274 trnH-psbA, may provide improved sensitivity to pollen analyses (Richardson et al. 2015b).

275 Despite potential limitations, such as the discrimination capacity of DNA barcodes and

276 quantitative assessment of taxa, and the necessity of specific laboratory facilities and an

277 intensive bioinformatics pipeline, DNA metabarcoding has high potential as an approach to

278 analyse, for example, pollen and fungi present in the environment.

279 People are exposed to pollen not only outdoors but also indoors. In fact, the question of the

280 remanence of pollen grains indoors is important, because allergic patients could get symptoms

281 from the indoor pollen far away from the pollination period. Besides pollen, indoor air typically

282 contains also other biological particles, such as fungi, Adams et al. (2013) have surveyed

283 temporal variation in fungal assemblages, both indoors and outdoors, using ITS1

284 pyrosequencing. They discovered that indoors fungal assemblages were strongly determined by

285 dispersal from outdoors. Additionally, there are specific diversity-related considerations, as

286 pointed out by Dannemiller et al. (2014), who demonstrated significant associations between low

287 fungal diversity in indoor air and childhood asthma development in a low-income, Mexican

288 immigrant community in the USA. The indoor air study by Dannemiller et al. (2014) provides

289 support for the so-called biodiversity hypothesis that proposes a connection between biodiversity

290 and allergic diseases that has been provided in several recent investigations (e.g. Hanski et al.

291 2012; Ruokolainen et al. 2015). An air quality problem may then rather arise from the presence

292 of certain types of pollen than plentiful diversity. 
The used method, DNA metabarcoding, is a potentially effective approach to determine the

294 taxonomic composition and diversity of pollen and possible other plant particles, and it may be

295 suitable for pollen monitoring both indoors and outdoors. In this study, great variation in

296 pollen/plant diversities were detected among buildings. Yet, considerable diversities were found

297 both in winter and summer, which shows that substantial amounts of pollen produced in summer

298 enter buildings and stay there throughout the year.

299

300 Acknowledgements - We thank the City of Helsinki representatives for providing sampling sites.

301 This work was supported by the Marjatta and Eino Kolli Foundation through a research project

3021055 to H. Korpelainen. The experiments comply with the current laws of the country, in which

303 they were performed.

304

305

References

306

Adams, R.I. et al, D. 2013. Dispersal in microbes: fungi in indoor air are dominated by outdoor air and show dispersal limitation at short distances. - The ISME Journal 7: 1262-1273.

Bohmann, K. et al. 2014. Environmental DNA for wildlife biology and biodiversity monitoring. - Trends Ecol. Evol. 29: 358-367.

Brown, E.A. et al. 2015. Divergence thresholds and divergent biodiversity estimates: can metabarcoding reliably describe zooplankton communities. - Ecol. Evol. 5: 2234-2251.

Bruni, I. et al. 2015. A DNA barcoding approach to identify plant species in multiflower honey. - Food Chem. 170: 308-315.

Castelino, M. et al. 2017. Optimisation of methods for bacterial skin microbiome investigation: primer selection and comparison of the 454 versus MiSeq platform. - BMC Microbiol. 17: 23. CBOL Plant Working Group 2009. A DNA barcode for land plants. - Proc. Natl. Acad. Sci. USA 
Chapman, M.D. et al. 2007. Nomenclature and structural biology of allergens. - J. Allergy Clin. Immunol. 119: 414-420.

Cornman, R.S. et al. 2015. Taxonomic characterization of honey bee (Apis mellifera) pollen foraging based on non-overlapping paired-end sequencing of nuclear ribosomal loci. - PLoS ONE 10(12): e0145365.

Crameri, R. et al. 2014. Fungi: the neglected allergenic sources. - Allergy 69: 176-185.

324 Dannemiller, K.C. et al. 2014. Next-generation DNA sequencing reveals that low fungal diversity in house dust is associated with childhood asthma development. - Indoor Air 24: 236-247.

Doyle, J.J. and Doyle, J.L. 1987. A rapid DNA isolation procedure for small quantities of fresh leaf tissue. - Phytochem. Bull. 19: 11-15.

Galimberti, A. et al. 2014. A DNA barcoding approach to characterize pollen collected by honeybees. - PLOS ONE 9(10): e109363.

Hanski, I. et al. 2012. Environmental biodiversity, human microbiota, and allergy are interrelated. - Proc. Natl. Acad. Sci. USA 109: 8334-8339.

Hawkins, J. et al. 2015. Using DNA metabarcoding to identify the floral composition of honey: a new tool for Investigating honey bee foraging preferences. - PLOS ONE 10(8): e0134735.

Heckenhauer, J. et al. 2016. Universal multiplexable matK primers for DNA barcoding of angiosperms. - Appl. Plant Sci. 4(6): 1500137.

Jantunen, J. et al. 2012. Allergy symptoms in relation to alder and birch pollen concentrations in Finland. - Aerobiol. 28: 169-176.

339 Keller, A. et al. 2015. Evaluating multiplexed next-generation sequencing as a method in 340 palynology for mixed pollen samples. - Plant Biol. 17: 558-566.

341 Khansari, E. et al. 2012. Pollen morphology of Campanula (Campanulaceae) and allied genera in 342 Iran with special focus on its systematic implication. - Flora 207: 203-211. 
343 Korpelainen, H. and Pietiläinen, M. 2017. Diversity of indoor fungi as revealed by DNA

$344 \quad$ barcoding. - Genome 60: 55-64.

345 Korpelainen, H. et al. 2016. Effective detection of indoor fungi by metabarcoding. - Ann.

$346 \quad$ Microbiol. 66: 495-498.

347 Kozich, J.J. et al. 2013. Development of a dual-index sequencing strategy and curation pipeline

348 for analyzing amplicon sequence data on the 1MiSeq Illumina sequencing platform. - Appl.

$349 \quad$ Envir. Microbiol. 79: 5112-5120.

350 Kraaijeveld, K. et al. 2015. Efficient and sensitive identification and quantification of airborne 351 pollen using next-generation DNA sequencing. - Mol. Ecol. Res. 15: 8-16.

352 Nelson, M.C, et al. 2014. Analysis, optimization and verification of Illumina-generated 16S 353 rRNA gene amplicon surveys. - PLoS ONE 9(4): e94249.

354 Parducci, L. et al. 2013. Molecular- and pollen-based vegetation analysis in lake sediments from 355 central Scandinavia. - Mol. Ecol. 22: 3511-3524.

356 Pichot, C. et al. 2015. Inference of the pollen penetration and remanence into dwellings using 357 seasonal variation of indoor/outdoor pollen counts. - Aerobiol. 31: 315-322.

358 Richardson, R.T. et al.2015a. Application of ITS2 metabarcoding to determine the provenance of 359 pollen collected by honey bees in an agroecosystem. - Applic. Plant Sci. 3(1): 1400066.

360 Richardson, R.T. et al. 2015b. Rank-based characterization of pollen assemblages collected by 361 honey bees using a multi-locus metabarcoding approach. - Applic. Plant Sci. 3(11): 1500043. 362 Ruokolainen, L. et al. 2015. Green areas around homes reduce atopic sensitization in children. 363 Allergy 70: 195-202.

364 Shannon, C.E. 1948. A mathematical theory of communication. - Bell Syst. Techn. J. 27: 379$365 \quad 423,623-656$.

366 Sickel, W. et al. 2015. Increased efficiency in identifying mixed pollen samples by meta367 barcoding with a dual-indexing approach. - BMC Ecology 15(20). 
Taberlet, P. et al. 2012. Towards next-generation biodiversity assessment using DNA barcoding. - Mol. Ecol. 21: 2045-2050. 


\section{$370 \quad$ Figure legends}

371

372 Figure 1. Percentages (\%) of sequences corresponding wild, garden/crop plants, indoor house

373 plants, and non-domestic fruit or other plant material in five buildings, including two university

374 office buildings, two nursery schools and a farmhouse, based on ITS2 sequences. Each pooled

375 sample included sampling of both horizontal and vertical surfaces. Sequencing for January and

376 July 2013 samples were conducted using 454 FLX pyrosequencing, while sequencing for

377 January and July 2014 samples were performed using Illumina MiSeq sequencing. 
Table 1. Taxonomic diversity of indoor plant material (mainly pollen) at family and genus level in five buildings, including two university office buildings, two nursery schools and a farmhouse, based on ITS2 sequences. Each pooled sample included sampling of both horizontal and vertical surfaces. Range of variables among individual samples is given in parentheses. Sequencing for January and July 2013 samples were conducted using 454 FLX pyrosequencing, while sequencing for January and July 2014 samples were performed using Illumina MiSeq sequencing. N, number of taxa; H, Shannon's diversity index.

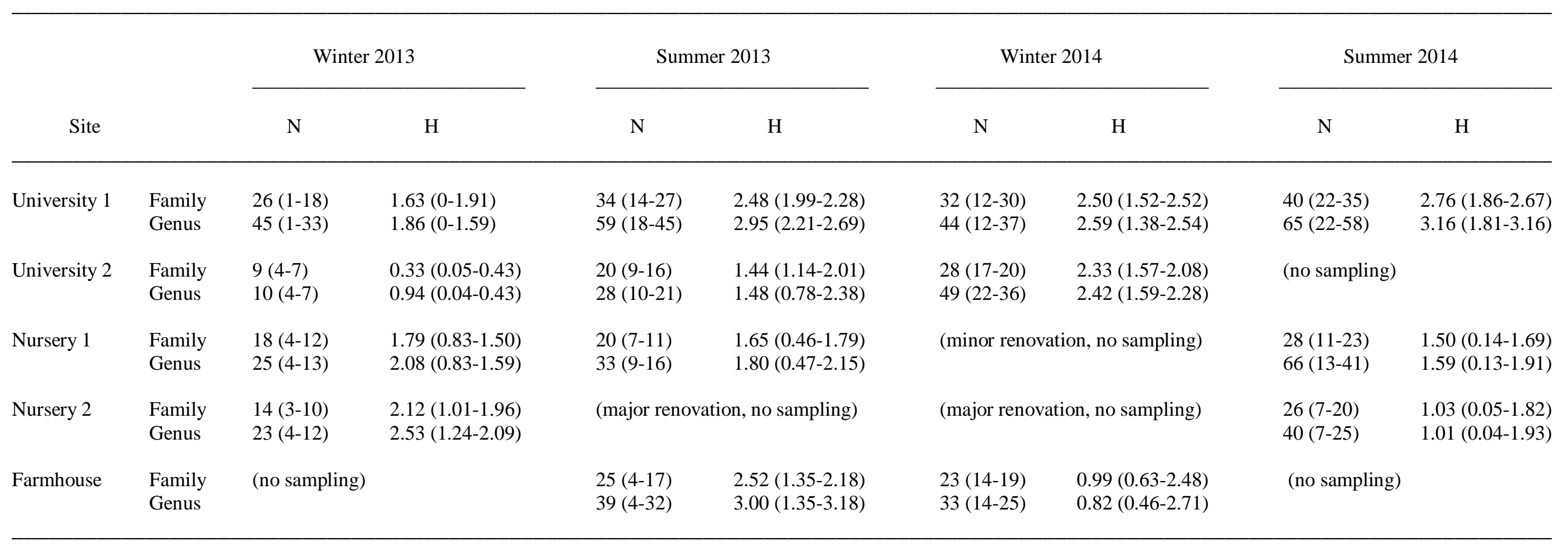


Table 2. Five most frequent plant genera and their proportions (\%, in parentheses) in five buildings, including two university office buildings, two nursery schools and a farmhouse, based on ITS2 sequences. Each pooled sample included sampling of both horizontal and vertical surfaces. Sequencing for January and July 2013 samples were conducted using 454 FLX pyrosequencing, while sequencing for January and July 2014 samples were performed using Illumina MiSeq sequencing.

\begin{tabular}{|c|c|c|c|c|}
\hline Site & Winter 2013 & Summer 2013 & Winter 2014 & Summer 2014 \\
\hline University 1 & $\begin{array}{l}\text { Aegopodium }(56.5) \\
\text { Acer }(11.3) \\
\text { Mitella }(7.4) \\
\text { Cannabis }(4.2) \\
\text { Elymus }(2.8)\end{array}$ & $\begin{array}{l}\text { Saintpaulia }(27.7) \\
\text { Brassica }(9.1) \\
\text { Dioscorea }(7.0) \\
\text { Camelina }(4.8) \\
\text { Juglans }(4.8)\end{array}$ & $\begin{array}{l}\text { Betula }(26.1) \\
\text { Cucurbita }(18.8) \\
\text { Helianthus }(10.8) \\
\text { Syringa }(9.3) \\
\text { Brassica }(6.5)\end{array}$ & $\begin{array}{l}\text { Betula }(14.3) \\
\text { Capsella }(13.3) \\
\text { Artemisia }(12.4) \\
\text { Solanum }(11.2) \\
\text { Brassica }(4.1)\end{array}$ \\
\hline University 2 & $\begin{array}{l}\text { Brassica }(55.0) \\
\text { Coincya }(36.4) \\
\text { Fagopyrum }(7.9) \\
\text { Elymus }(1.3) \\
\text { Hordeum }(1.3)\end{array}$ & $\begin{array}{l}\text { Fallopia }(64.2) \\
\text { Mycelis }(12.9) \\
\text { Pinus }(4.8) \\
\text { Arrhenatherum (3.4) } \\
\text { Saintpaulia }(2.6)\end{array}$ & $\begin{array}{l}\text { Myosotis }(31.2) \\
\text { Betula }(26.7) \\
\text { Daucus }(7.1) \\
\text { Brassica }(4.5) \\
\text { Syringa }(3.6)\end{array}$ & (no sampling) \\
\hline Nursery 1 & $\begin{array}{l}\text { Betula }(30.7) \\
\text { Gerbera }(26.4) \\
\text { Rubus }(13.2) \\
\text { Pisum }(8.0) \\
\text { Lathyrus 5.7) }\end{array}$ & $\begin{array}{l}\text { Ficus }(52.4) \\
\text { Cinnamomum (18.5) } \\
\text { Pisum }(5.9) \\
\text { Betula }(4.9) \\
\text { Saintpaulia }(3.2)\end{array}$ & (minor renovation, no sampling) & $\begin{array}{l}\text { Betula }(47.9) \\
\text { Brassica }(20.0) \\
\text { Daucus }(18.3) \\
\text { Pisum }(6.5) \\
\text { Artemisia }(1.1)\end{array}$ \\
\hline Nursery 2 & $\begin{array}{l}\text { Brassica }(28.4) \\
\text { Betula }(10.1) \\
\text { Secale }(10.1) \\
\text { Ficus }(9.2) \\
\text { Triticum }(6.4)\end{array}$ & (major renovation, no sampling) & (major renovation, no sampling) & $\begin{array}{l}\text { Betula }(97.9) \\
\text { Acer }(0.3) \\
\text { Brassica }(0.2) \\
\text { Prunus }(0.2) \\
\text { Urtica }(0.2)\end{array}$ \\
\hline Farmhouse & (no sampling) & $\begin{array}{l}\text { Saintpaulia }(16.5) \\
\text { Brassica }(15.7) \\
\text { Lactuca }(8.4) \\
\text { Syringa }(6.0) \\
\text { Polygonum }(5.6)\end{array}$ & $\begin{array}{l}\text { Syringa }(83.4) \\
\text { Betula }(8.5) \\
\text { Anthriscus }(0.9) \\
\text { Pinus }(0.9) \\
\text { Brassica }(0.8)\end{array}$ & (no sampling) \\
\hline
\end{tabular}


Fig. 1.

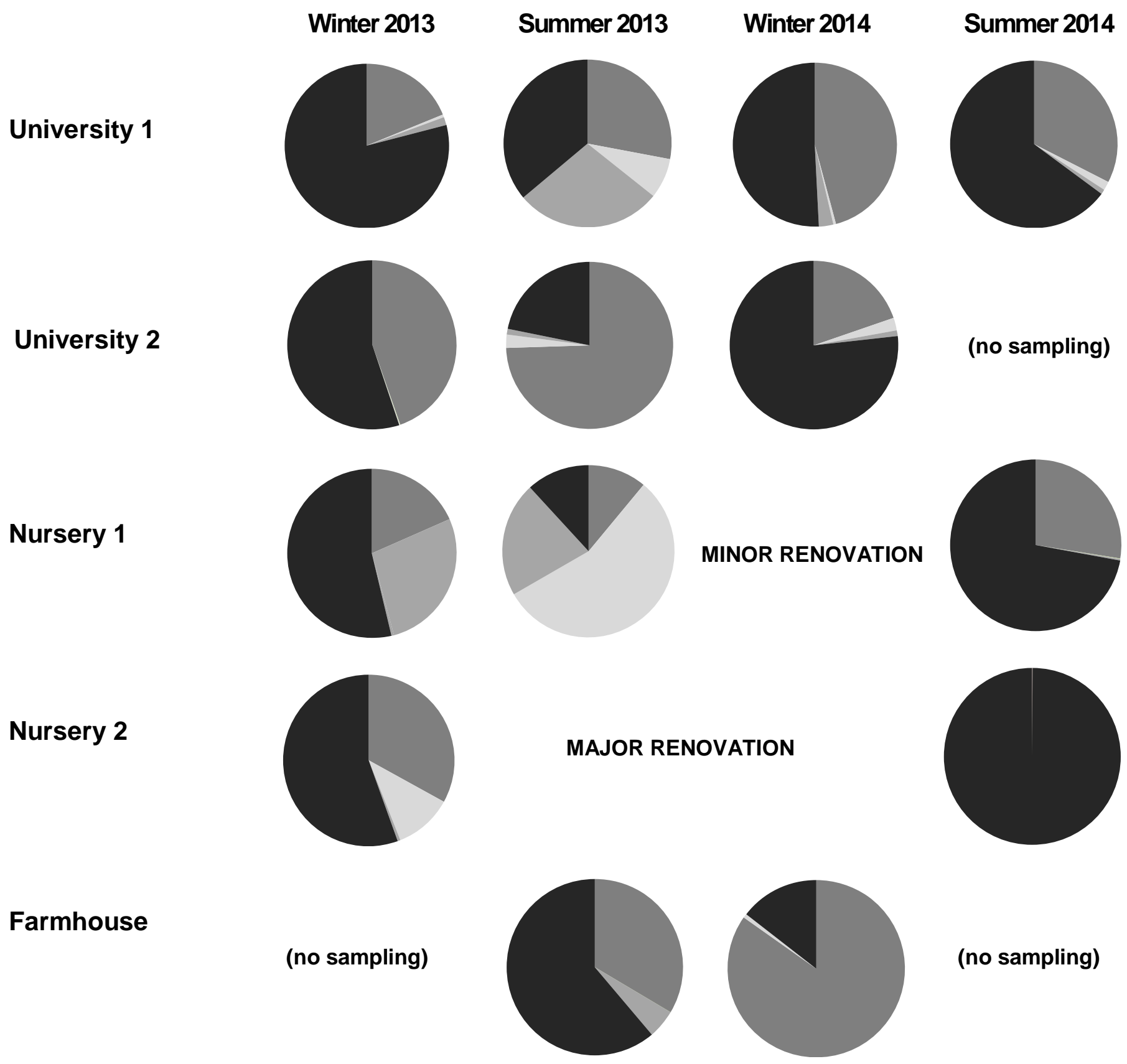

(no sam

Wild plants

Garden/crop plants

Indoor house plants

Non-domestic fruit or other plant material 